\title{
Rajyoga Meditation Experience Induces Enhanced Positive Thoughts and Alters Gray Matter Volume of Brain Regions: A Cross-sectional Study
}

\author{
Ramesh Babu M G ${ }^{1} \cdot$ Rajagopal Kadavigere ${ }^{2} \cdot$ Prakashini Koteshwara ${ }^{2} \cdot$ Brijesh Sathian $^{3} \cdot$ Kiranmai S. Rai $^{1}$ (D)
}

Accepted: 10 April 2021 / Published online: 8 May 2021

(C) The Author(s) 2021

\begin{abstract}
Objectives Many studies on various meditation types have reported regional gray matter volume changes using voxel-based morphometric analysis of structural MRI, but there are no studies done on structural MRI of Rajyoga meditators. The objective of the present study is to analyze and compare gray matter volume changes of brain regions in meditators and non-meditators and further study the effects of meditation experience on alterations in various brain regions. These regions were then correlated and compared to positive thought scores of participants.

Methods Forty participants in each group (closely matched for age, gender, and handedness) were selected after obtaining their informed consent, and voxel-based morphometric analysis was carried out using their structural MRI scans.

Results On voxel-wise comparison of the brain scans, meditators were observed to have significantly higher global gray matter volume and significant regional gray matter volume increases in the right superior frontal gyrus, left inferior orbitofrontal cortex, left inferior parietal gyrus, left posterior cerebellum, left middle temporal gyrus, bilateral precuneus, and cuneus. Additionally, long-term meditators particularly had significantly higher positive thinking scores compared to non-meditators. On multiple regression analysis, gray matter volume of the left superior parietal gyrus and left inferior parietal gyrus had a positive association, whereas the left posterior cerebellum had a negative association with hours of meditation experience. With the positive thoughts score, a significant relationship was found in the right superior temporal gyrus in meditators.

Conclusions These findings indicate that Rajyoga meditation experience/practice enhances gray matter volume of specific brain regions and positive thoughts.
\end{abstract}

Keywords MRI · Rajyoga meditation · VBM · Positive thoughts

During the developmental process of the brain, a considerable increase in total cerebral volume is observed between childhood and adolescence. As age advances, cerebral volume progressively declines through the second and third decades due to synaptic pruning, white matter development, and neuronal loss (Giedd et al., 2014; Lenroot et al., 2007; Mills \& Tamnes, 2014; Streit et al., 2004). Although there is a decline in the gray matter

Kiranmai S. Rai

hod.physio@gmail.com; kiranmai.rai@manipal.edu

1 Department of Physiology, Melaka Manipal Medical College, MAHE, Manipal, Karnataka 576104, India

2 Department of Radiodiagnosis and Imaging, Kasturba Medical College, MAHE, Manipal, Karnataka, India

3 Geriatrics and Long Term Care Department, Rumailah Hospital, PO Box-3050, Doha, Qatar
(GM) of the brain as part of the normal aging process or in pathological conditions, it is possible to conserve or increase gray matter volume (GMV) in adulthood by developing cognitive skills through proper training (Schlaug, 2015). Research reports suggest that an increase in GMV can be achieved by various methods like repeated stimulation of specific brain regions, learning a second language, and meditation training (Hölzel et al., 2011; May et al., 2007; Pliatsikas, 2020) .

For thousands of years, meditation has been used as a tool to train the mind and achieve harmony between the physical, mental, intellectual, and spiritual personalities of humans (Fox et al., 2016). Learning meditation or meditation intervention has been associated with morphometric changes in the brain when compared to controls and is observed both in crosssectional and longitudinal imaging studies (Fox et al., 2012; Hölzel et al., 2011; Luders et al., 2011). Studies provide evidence that short- and long-term meditation practice brings 
about changes in GM of the brain, specifically increasing density in the right inferior frontal region, with larger volumes in the orbitofrontal cortex and right hippocampus. These regions involve in emotional regulation and response control (Dodich et al., 2019; Luders et al., 2009). Meditation training induces neural plasticity in the brain similar to other forms of skill acquisition. Lazar et al. (2005) provided structural evidence for experience-dependent plasticity in the cortical regions in Buddhist insight meditators. Studies on different types of meditation provide evidence that the enhanced neural plasticity of GM is based on regularity and the type of meditation technique practiced (Engen et al., 2018; Hernández et al., 2016; Hölzel et al., 2008; Luders et al., 2009).

The effects of meditation practice on the brain were observed in different brain regions, possibly because of considerable heterogeneity among meditation techniques practiced. Studies show ample evidence that meditation practice causes structural changes in specific brain regions. These studies include findings of structural changes in the medial prefrontal cortex (PFC) that permits understating of self and others (Frith \& Frith, 1999; McAlonan et al., 2005); superior frontal gyrus (SFG), ventromedial and ventrolateral orbitofrontal cortices along with inferior parietal, and superior temporal cortices which involve attentional control and introspective perception (Hernández et al., 2016; Hopfinger et al., 2000); precuneus/ posterior cingulate cortex (PCC) along with middle temporal gyrus (MTG) and middle frontal gyrus that enables better control over mind wandering and mediates happiness (Panda et al., 2016; Sato et al., 2015); hippocampus that maintains emotional response (Davidson et al., 2000; Luders et al., 2013); and occipital regions such as cuneus, superior, middle, and inferior occipital cortices that are involved in visual attention (Corbetta et al., 1998; Hopfinger et al., 2000).

Most of the meditation practices that focus on their thoughts or breathing are closed-eye meditation techniques. However, Rajyoga meditation (RM) is an open-eye meditation technique taught by the Brahma Kumaris's organization (Brahmakumaris, 2020; Ramesh et al., 2013). The details of RM practice are described in various papers and also posted in the Brahma Kumaris's organization web page. Briefly, during the practice of RM, an individual is instructed to realize himself/herself as an eternal form of self/soul and to gaze on the point of light, which is considered as Supreme Soul/God Father. Also, individuals are instructed to think positively during meditation. Thinking and feeling good/positive about the self by pondering on virtues/positive thoughts (PT) including peace, love, happiness, and bliss that reside in an individual are described as positive thinking in the context of RM practice (Gupta et al., 2011; Ramsay et al., 2010; Telles et al., 1993). Incorporation of PT may reduce preservative behavior, modulate cognitive control, and provide flexible updates of working memory (Dreisbach, 2006; Sharma et al., 2018). Despite altered circumstances, whether it is positive or negative, the propensity of positive thinking can influence a person's feelings of wellbeing (Diener et al., 2009). Over time, RM practice harmonizes spiritual, mental, and physical energy to raise up the inner strength and enhanced cognitive control in order to be more focused to lead a stress-free, healthy, satisfied, and happy life (Gupta et al., 2011; Ramesh et al., 2013).

Currently, neurocognitive research on RM is gaining more attention, and a few studies have been conducted using electrophysiological and imaging modalities. A study by Sharma et al. (2018) in long-term RM practitioners was observed to show alpha and theta wave pattern in frontal and parietal areas of the brain while maintaining meditative experience. This suggests that RM practice has impact on the brain regions involved in the management of selective and sustained attention while dealing with the cognitive and emotional aspects. Studies on both the short- and long-term meditation practitioners proved their ability to attain a stable state in meditation in a few minutes. However, long-term practitioners, under varying external conditions, can attain this state within a minute. Interestingly, these achievements were made with open-eye during meditation which has potential applications in daily life (Nair et al., 2017). Diffusion tensor imaging study on long-term RM practitioners has reported an increased white matter (WM) integrity in corpus callosum which is essential for the functional integrity between hemispheres at the time of high attention demand (Sharma et al., 2018). A study in RM practitioners by Panda et al. (2016) have observed changes in the default mode network's spatial extents and temporal dynamics during meditation. RM practice has an impact on GMV of reward processing regions of the brain and helps to achieve higher happiness levels (Babu et al., 2020). Although these studies provide evidence of the influence of RM practice on the brain, there are no structural MRI studies elucidating the influence of RM practice on PT and GMV changes in specific brain regions of RM practitioners.

The hypotheses of the present study are that RM practice would cause structural alterations (GMV changes) in brain regions associated with meditation experience and positive thinking. The objective of this study was to elucidate GMV changes in different regions of the brain from structural MRI of RM practitioners, analyze using voxel-based morphometric (VBM) technique, and compare the same with age, gender, and handedness matched non-meditators (NM). Additionally, these specific brain regions were correlated to hours of meditation experience and PT scores within the group of RM practitioners.

\section{Methods}

\section{Participants}

All participants recruited for this study were provided with a complete explanation of the study procedures, including MRI safety precautions, and informed consent was obtained in the 
consent form prior to the study. Eighty participants, including $\mathrm{NM}$ and RM practitioners ( $n=40$ /group), were selected for this study. The regular RM practitioners were recruited from Brahma Kumaris's RM centers in the areas of Udupi and Mangalore districts of Karnataka. The NM who volunteered to participate in this study were recruited from the same areas as those from where RM practitioners were recruited. The participants with metabolic disorders, mental disorders, physical illness, addiction to drugs or alcohol, and practicing other types of meditation were not selected for this study. All participants were matched for age (NM (mean $\pm \mathrm{SD}, 41.20 \pm 7.94$ years); $\mathrm{RM}$ practitioners (mean $\pm \mathrm{SD}, 40.07 \pm 7.1$ years)), gender (male and female: $n=20$ /group), and handedness (all are right-handed $n=39 /$ group, except one left-handed/group). Among RM practitioners, the total hours of meditation were calculated as Total hours $=($ hours of meditation/day $) \times(365$ days/year) $\times$ (years of experience), and mean meditation experience was $8022.24 \mathrm{~h}(\mathrm{SD}=8767.69)$. Though the participants were matched for age, gender, and handedness, no matching was found in the education levels of participants. The participants who had completed school or diploma were 18 in NM and 21 in RM; holding a bachelor degree, 2 in NM and 14 in RM; completed post-graduate, 16 in NM and 5 in RM; and completed Ph.D., 4 in NM and none in RM. Since education levels showed significant difference $(p<0.0001)$ in this study and has a strong influence on brain morphometry, education levels were included as a nuisance covariate for VBM analysis (Archer et al., 2018; Boller et al., 2017).

\section{Procedures}

\section{Image Acquisition}

Brain structural MRI scans of all the participants were obtained using a 1.5T Philips Achieva scanner with an 8 SENSE head coil. A T1-weighted high-resolution 3D image was acquired by using turbo field echo (TFE) sequence repetition time (TR) $7 \mathrm{~ms}$, echo time (TE) $3.703 \mathrm{~ms}$, flip angle $8^{\circ}$, voxel resolution $1 \times 1 \times 1 \mathrm{~mm}^{3}$, and field of view (FOV) $256 \mathrm{~mm}$ which yielded 175 slices encompassing the whole brain. All the images were examined by an experienced radiologist for any space-occupying lesion or visible artifact. None of the data were excluded, as there was no space-occupying lesion or visible artifacts in any of the scans collected for the study.

\section{Image Preprocessing}

The underlying specific regional changes in the GMV of the brain can be more accurately detected and gauged by using VBM analysis, an advanced neuroimaging analytical technique that measures voxel-wise changes of regional volume differences (Ashburner \& Friston, 2000) in structural MRI by statistically comparing between regions of the brain of participants from NM and RM groups. In this study, the VBM analytical method is applied using CAT12 (computational anatomical toolbox-version 12.6) (http://dbm.neuro. uni-jena.de/cat/) installed in the SPM12 (statistical parametric mapping - version 12) software (ftp://ftp.fil.ion. ucl.ac.uk/spm), and MATLAB software is used as a common platform for these software.

By using MRIConvert version 2.1.0 (https://lcni.uoregon. edu/downloads/mriconvert), all the DICOM images were converted into the NIfTi format. A manual reorientation of all the images was done by fixing the anterior commissure of the brain as the origin to match with the reference template provided in the SPM canonical template. All the preprocessing steps were carried out using the CAT12 software tool as described in the VBM manual (http://www. neuro.uni-jena.de/cat12/CAT12-Manual.pdf) and as explained in detail in VBM studies (Agroskin et al., 2014; Babu et al., 2020; Raschle et al., 2018; Tang et al., 2012). Further, a sample homogeneity test was conducted for all the preprocessed data, and all images were carefully inspected for image quality. Since the overall quality of all the images was good, all the images were included in the analysis.

Further, values were generated using the estimate option in the CAT12 software tool for volumes of GM, WM, cerebrospinal fluid (CSF), and total intracranial volume (TIV) from each image. GMVs of 122 brain regions were extracted for each participant, based on automated anatomical labeling (AAL) atlas, during preprocessing steps by using the CAT12 tool in the expert mode. For VBM statistical analysis, an 8$\mathrm{mm}$ full width at half maximum (FWHM) isotropic Gaussian kernel was used to smooth all the preprocessed images.

\section{Generation of Masks}

Using the WFU-Pickatlas tool (http://fmri.wfubmc.edu/ software/pickatlas), the 3D sphere masks were generated. The differences between GMVs of 122 brain regions of NM and RM practitioners were obtained using the AAL atlas and analyzed statistically. On comparison of these regions between NM and RM practitioners, the regions that showed a significant difference $(p<0.05)$ and a trend toward significant difference $(p<0.1)$ after adjusted for TIV and age were selected for generating the spherical region of interest (ROI) masks as shown in Table S1 (Supplementary Materials). In addition, since RM is an open-eye meditation technique, cuneus, a primary occipital region, was also considered for creating a spherical bilateral union mask, and the radius was centered at $\mathrm{x}, \mathrm{y}$, and $\mathrm{z}$ coordinates $\pm 12,-80$, and 26 (Hauswald et al., 2015). Totally 15 bilateral union masks for different regions were created. The size of the mask was $8 \mathrm{~mm}$ for all the regions except the orbitofrontal cortex (OFC) and cerebellum. Considering the larger size of these regions and the numbers of studies reported in different types of 
meditation, a larger mask ( $16 \mathrm{~mm}$ ) was chosen for OFC and cerebellum. The masks created by the WFU-Pickatlas tool had $2 \mathrm{~mm}$ voxel dimensions by default, which is different from the VBM output images which have $1.5-\mathrm{mm}$ voxel dimensions. Therefore, to achieve the same voxel dimensions, all the generated ROI masks were registered with a normalized image from VBM output as a reference image by applying the coregister (re-slice) option available in SPM12.

\section{Measures}

\section{Thought Pattern Questionnaire (TPQ)}

TPQ, a cognitive scale, was constructed and designed to measure PT score. The TPQ consists of 28 items, scored based on 5 points Likert scale, with a response format ranging from "strongly agree" to "strongly disagree." The total PT score can be obtained by adding all the scores of individual items. Reliability analysis of the TPQ was performed earlier in a pilot study (see Supplementary Materials S2 for more details on TPQ). The individual PT score obtained by RM practitioners was further correlated to hours of meditation experience and the brain regions of their structural MRI.

\section{Data Analyses}

The basic statistical model, full factorial design, was selected from the CAT12 toolbox for a $t$-test to elucidate the voxelwise GMV changes in structural MRI of NM and RM practitioners. The confounding effect, which is inherent due to the variable size of the head/brain, age, and education level, was removed by considering age, TIV, and levels of education as a nuisance covariate. To prevent edge effect along the boundaries of GM and WM, an absolute threshold masking with a value of 0.1 was used. To measure group differences for $\mathrm{NM}>$ RM practitioners $(1-1)$ and for RM practitioners $>$ NM $(-11)$ $t$-contrasts were used. For voxel-wise comparison, a threshold-free cluster enhancement (TFCE) method with 5000 permutations was applied (Smith and Nichols, 2009) by using the TFCE software (http://dbm.neuro.uni-jena.de/ tfce/) version 185. It is a non-parametric statistic that integrates the focal effects of large voxel height and cluster size in the data obtained by using the VBM method. Though the TFCE analysis requires minimum or no smoothing (Li et al., 2017), smoothed images with an 8-mm kernel size were used in the present study, which is similar to the previous VBM studies (Babu et al., 2020; Raschle et al., 2018). The small volume correction (SVC) option was utilized in TFCE analysis to find out the GMV changes in the selected ROIs.

Additionally, multiple regression analysis was applied using hours of meditation experience and PT scores of RM practitioners as independent variables, respectively. Since a significant positive association $(p=0.024)$ between hours of meditation experience and PT scores of meditators was obtained, this analysis was performed separately to evade multicollinearity issues. The confounding effect of age, TIV, and education levels were eliminated by entering these variables as nuisance covariates. To find out positive and negative correlations, $t$-contrasts $(1)$ and $(-1)$ were used, and SVC was applied using ROI masks in TFCE analysis. The resultant SPM statistical maps from the TFCE analyses were considered as significant at a threshold value of $p<0.05$, corrected for family-wise error (FWE). A single-subject representative image in SPM was overlaid with the statistical map to report the results.

To find out the group differences for global GM, WM, and CSF volumes, the ANCOVA method was applied using SPSS software version 22 in a multivariate model adjusted for TIV and age. For group differences in TIV, a univariate model, with age of the participant as a nuisance covariate, was used. A $t$-test was applied to compare PT scores of NM and RM practitioners. A bivariate correlation analysis was performed to find out the association between the hours of meditation experience and PT score. The mean meditation experience of RM practitioners was $8022.24 \mathrm{~h}(\mathrm{SD}=8767.69)$ which was not normally distributed. A normalized mean hour of experience was calculated, and the normalized mean hours of experience was $3.64(\mathrm{SD}=0.52)$ and Spearman's rho value was reported from the correlation analysis. Further, the GMV of brain regions that were identified as significant in multiple regression analysis were extracted based on the AAL atlas and were correlated with PT score as well as hours of meditation experience adjusted for TIV and age. Additionally, based on the median hours $(3741 \mathrm{~h})$ of meditation experience, RM practitioners were categorized into short-term $(n=20)$ and long-term $(n=20)$ meditators for comparison of extracted regional GMV between these two categories of RM practitioners. Results are reported with significance at the 5\% alpha level.

\section{Results}

\section{Comparison of Global Brain Volume}

In comparison with TIV between NM and RM, no significant difference $\left(F_{(1,77)}=1.43, p=0.24\right.$, adjusted for Bonferroni correction) was observed between the groups by univariate analysis. However, in multivariate analysis, global GM, $\mathrm{WM}$, and CSF volumes between NM and RM practitioners, a significant increase $\left(F_{(3,74)}=4.44, p=0.038\right.$, adjusted for Bonferroni correction) was observed only in global GMV in $\mathrm{RM}$ practitioners (mean \pm SD: $563 \pm 70$ ) than $\mathrm{NM}$ (mean \pm SD: $548.99 \pm 56.71)$, as shown in Fig. 1. 


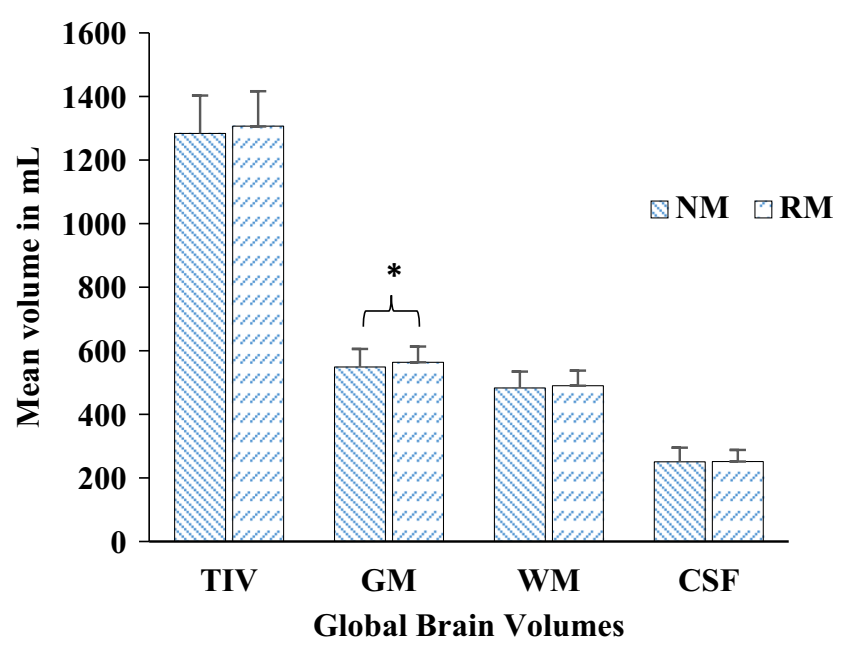

Fig. 1 Comparison of global mean volumes of TIV, GM, WM, and CSF between NM and RM practitioners. $* p<0.05$. TIV, total intracranial volume; GM, gray matter volume; WM, white matter volume; CSF, cerebrospinal fluid. NM, non-meditators; RM, Rajyoga meditation

\section{Voxel-Wise Comparison Analyses}

SVC method was first applied using ROI masks, and a significantly higher GMV was observed in the following regions, right SFG, left inferior OFC, left inferior parietal gyrus (IPG), bilateral precuneus, bilateral cuneus, and left posterior cerebellum, in RM practitioners when compared to the same in NM (Fig. 2A). The whole-brain voxel-wise comparison between NM and RM groups revealed a significantly higher GMV in the left MTG (Fig. 2B) in RM practitioners. The details of MNI coordinates, voxel size of the cluster, and $p$-value for identified brain regions are provided in Table 1.

\section{Association of GMV Changes in RM Practitioners with the Duration of Meditation Experience}

A significant positive association was found in left superior and inferior parietal regions, as well as a significant negative correlation in the left posterior cerebellum with hours of meditation experience, as shown in Fig. 3a. No significant positive or negative association with hours of meditation experience was observed for whole-brain voxel-wise correlations. Table 2 gives the details of voxel size in a cluster, MNI coordinates, and $p$ value for identified brain regions. On correlating the extracted regional GMV of the left superior parietal gyrus (SPG) with hours of meditation experience, a significant positive correlation was observed $(R=0.47, p=0.007)$ as shown in Fig. 3b. On comparing the extracted regional GMV of left SPG between short- and long-term RM practitioners, a higher GMV was found in long-term RM practitioners, whereas for GMV of left IPG and left posterior cerebellum, a higher GMV was observed in short-term RM practitioners as shown in Fig. 3c.

\section{Analysis of TPQ}

RM practitioners were observed to have significantly ( $t=$ 4.22, $d f=78, p=0.0001$ ) higher PT score (mean \pm SD 117 \pm 14.80 ), compared to NM (mean \pm SD $102.78 \pm 16.39$ ). Further on correlation analysis, PT score with normalized hours of meditation experience, a significant positive association (Spearman's rho $=0.356, p=0.024$ ) was found as shown in Fig. 4a. On comparing PT score between shortand long-term RM practitioners, long-term RM practitioners had significantly $(t=2.27, d f=38, p=0.029)$ higher PT score (mean \pm SD $122.55 \pm 14.66$ ) than short-term practitioners (mean \pm SD: $112.45 \pm 13.26$ ) as shown in Fig. 4b. On the voxel-wise correlation of PT score with brain regions, a significant positive association was found (Table 3) only with superior temporal gyrus (STG) and not for other ROIs, as shown in Fig. 5a. No significant positive or negative association with PT score was observed for whole-brain voxel-wise correlations. On correlation analysis with meditation experience and comparison analysis between short- and long-term practitioners with extracted regional GMV of STG, no significant results were observed as shown in Fig. 5b, c.

\section{Discussion}

The present study provides initial evidence on the association between PT score and morphometric changes analyzed by VBM method in various brain regions of RM practitioners. The mean TIV is found to be increased in the RM practitioners group, although it is not significant in this study. A significant increase in the mean global GMV was found in the RM practitioners group when compared to that of NM. Other meditation studies report a significant change in GMV of specific regions of the brain in meditators when compared with control. However, very few studies report a significant increase in global GMV. Hernández et al. (2016) found a larger global GMV in Sahaja Yoga meditation practitioners compared with that of NM, and it was predominantly on the right hemispheric brain areas. On comparing the hemispheric differences between meditators and control, Kurth et al. (2015) reported that the cluster-specific GMV was significantly more in the left hemisphere than the right. Although cluster-specific increased GMV on the left hemisphere in RM practitioners was identified, the specific hemispheric global GMV changes were not analyzed in the present study. In this study, a voxelwise comparison using the SVC method was applied first, as shown in Fig. 2A, B and Table 1. Accordingly, using this method, a significantly higher GMV was observed in the brain regions including the right SFG, left inferior OFC, left IPG, bilateral precuneus, bilateral cuneus, and left posterior cerebellum, as well as a significant increase in GMV of left MTG by voxel-wise comparison of whole-brain was observed. 

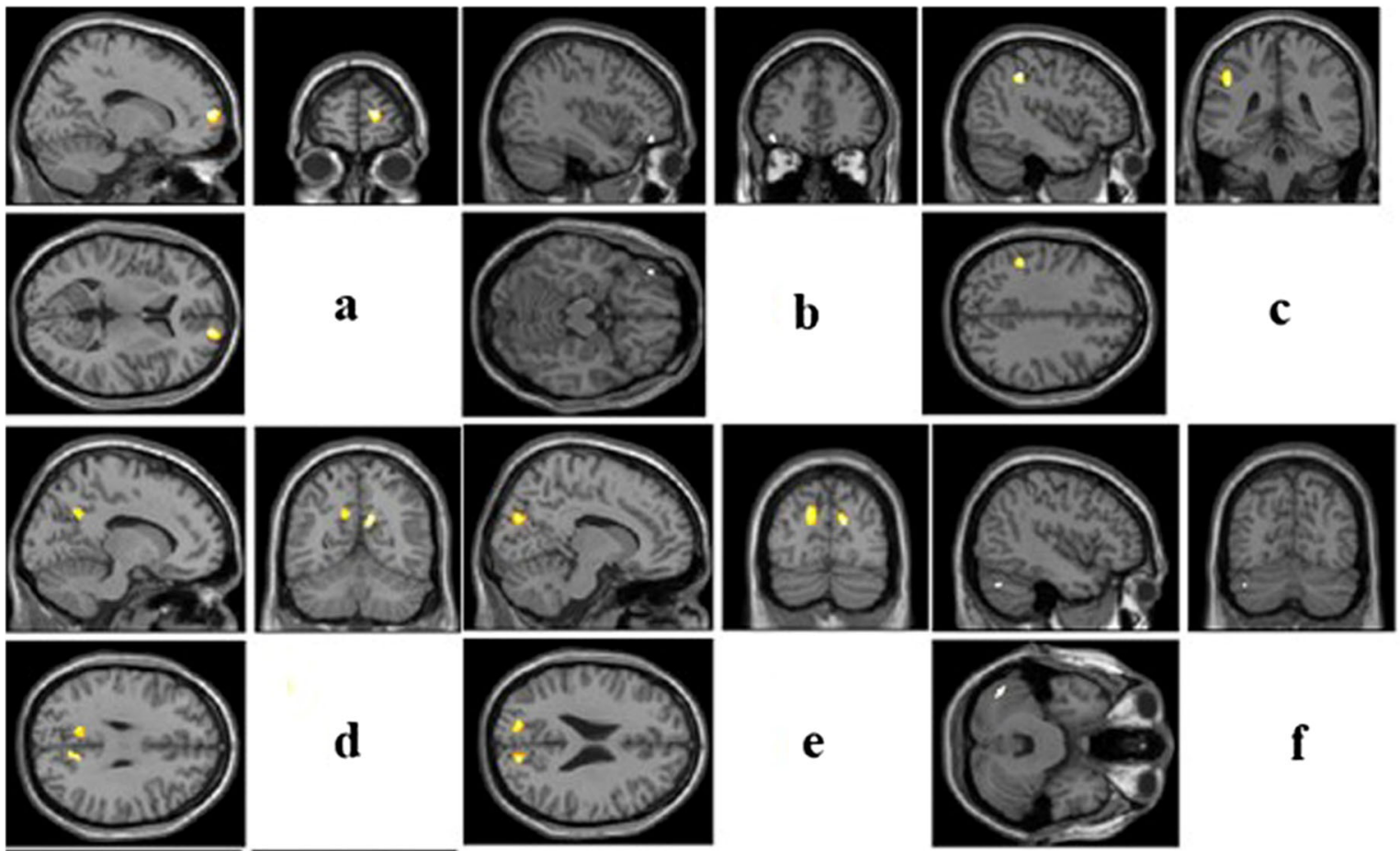

$\mathbf{A}$
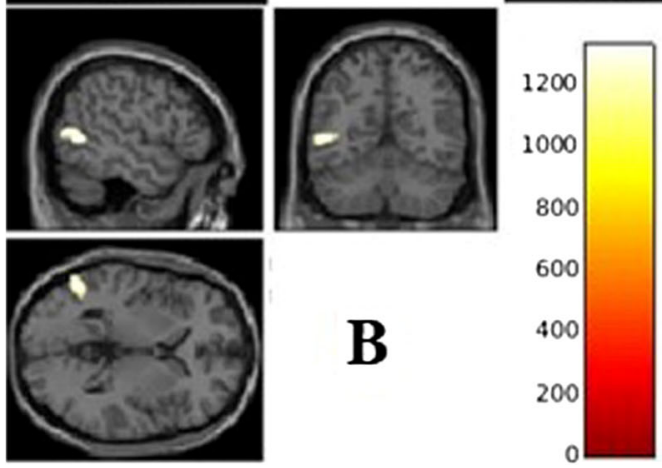

Fig. 2 (A) Representative sMRI image, showing significant (FWE TFCE corrected $p<0.05, d f=75$ ) GMV increase after applying SVC in the (a) right superior frontal gyrus, (b) left inferior orbitofrontal cortex, (c) left inferior parietal gyrus, (d) bilateral precuneus, (e) bilateral cuneus, and (f) left posterior cerebellum in RM practitioners. (B) Representative sMRI

image for whole-brain voxel-wise comparison showing significant (FWE TFCE corrected $p<0.05, d f=75$ ) increases in GMV in the left middle temporal gyrus in RM practitioners. TFCE, threshold-free cluster enhancement; SVC, small volume correction. Color bar indicates TFCE values
Table 1 Brain regions showing significant changes in GMV in $\mathrm{RM}$ practitioners compared to the same in NM

\begin{tabular}{|c|c|c|c|c|c|c|}
\hline \multirow[t]{2}{*}{ Regions } & \multirow[t]{2}{*}{ Side } & \multicolumn{3}{|c|}{ Coordinates $^{\#}$} & \multirow[t]{2}{*}{ Voxels ${ }^{@}$} & \multirow[t]{2}{*}{$p$-value* } \\
\hline & & $\mathrm{x}$ & $\mathrm{y}$ & $\mathrm{z}$ & & \\
\hline \multicolumn{7}{|c|}{ Voxel-wise comparison using small volume correction } \\
\hline Superior frontal gyrus & Right & 16 & 62 & 8 & 280 & 0.005 \\
\hline Inferior orbitofrontal cortex & Left & -38 & 42 & -16 & 45 & 0.037 \\
\hline \multirow[t]{2}{*}{ Precuneus } & Right & 10 & -58 & 27 & 264 & 0.011 \\
\hline & Left & -14 & -57 & 32 & 112 & 0.019 \\
\hline Inferior parietal gyrus & Left & -44 & -42 & 45 & 253 & 0.005 \\
\hline \multirow[t]{2}{*}{ Cuneus } & Right & 14 & -78 & 24 & 188 & 0.002 \\
\hline & Left & -14 & -81 & 28 & 359 & 0.004 \\
\hline Posterior cerebellum & Left & -42 & -70 & -32 & 46 & 0.037 \\
\hline \multicolumn{7}{|c|}{ Voxel-wise comparison of whole brain } \\
\hline Middle temporal gyrus & Left & -51 & -62 & 3 & 794 & 0.021 \\
\hline
\end{tabular}

*FWE TFCE corrected; ${ }^{*}$ peak coordinates in MNI space; ${ }^{\circledR}$ number of voxels in a cluster 

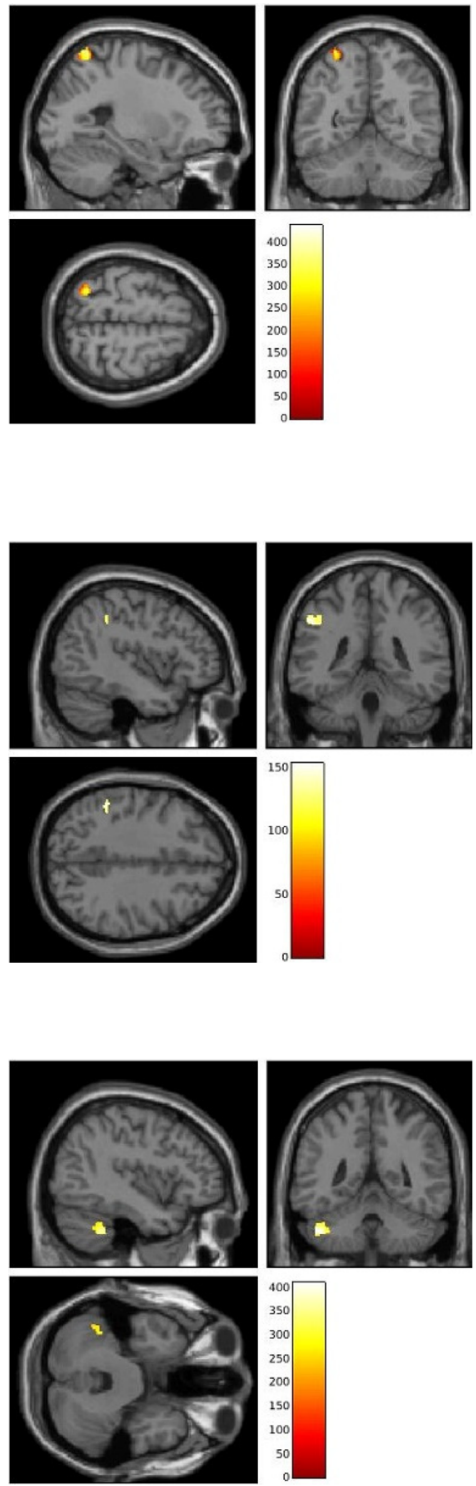

a

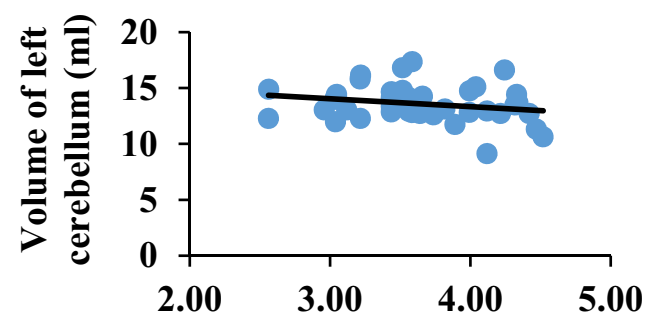

Hours of meditation experience (Normalized)

\section{b}
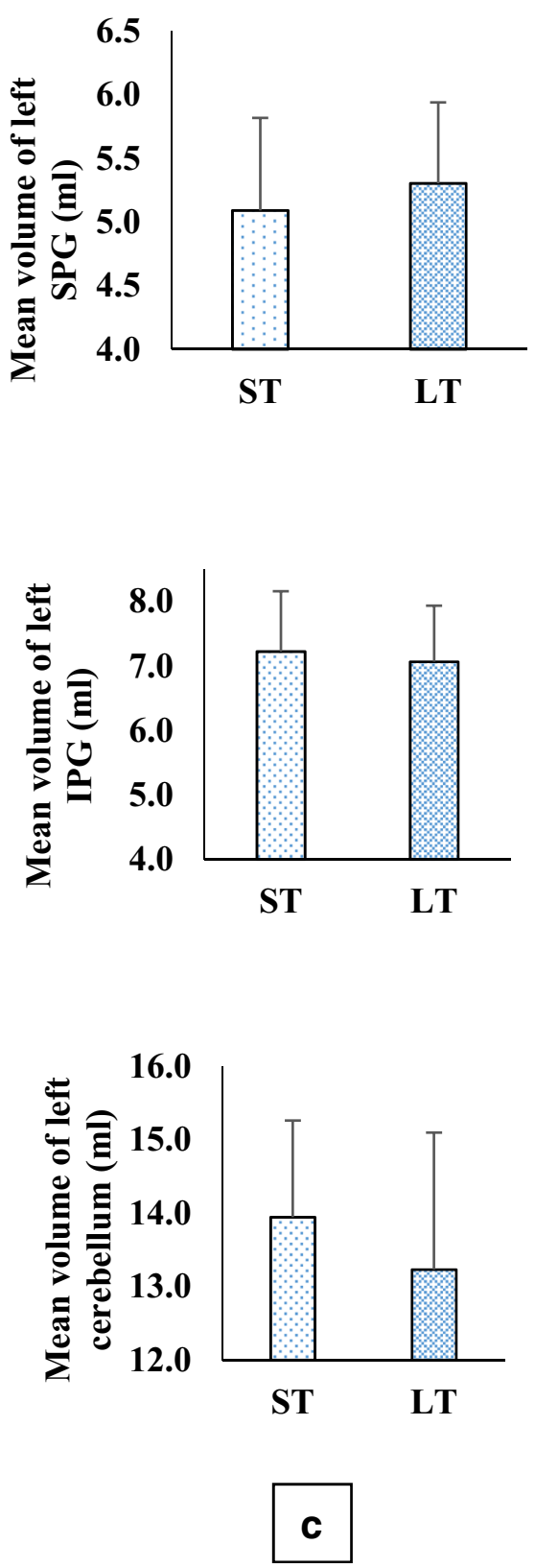

of left superior parietal gyrus with hours of meditation experience. $\mathbf{c}$ Box plot showing higher GMV in long-term RM practitioners in the left superior parietal gyrus, whereas in short-term RM practitioners, higher GMV observed in the left inferior parietal gyrus and posterior cerebellum. Color bar indicates TFCE values. TFCE, threshold-free cluster enhancement; SVC, small volume correction

study on Brain Wave Vibration meditators showed structural differences in both gray and white matters, particularly in the frontal cortex that is necessary for attention and emotional regulation (Kang et al., 2013). The superior frontal cortex, along with the inferior parietal and superior temporal cortices, is also involved in involuntary attentional control (Hopfinger et al., 2000). PFC activation is individually distributed and very much 
Table 2 Correlation of meditation experience in RM with hours of meditation practice

\begin{tabular}{|c|c|c|c|c|c|c|}
\hline \multirow[t]{2}{*}{ Regions } & \multirow[t]{2}{*}{ Side } & \multicolumn{3}{|c|}{ Coordinates $^{\#}$} & \multirow[t]{2}{*}{ Voxels ${ }^{@}$} & \multirow[t]{2}{*}{$p$-value } \\
\hline & & $\mathrm{x}$ & $\mathrm{y}$ & $\mathrm{z}$ & & \\
\hline \multicolumn{7}{|l|}{ Positively correlated } \\
\hline Superior parietal gyrus & Left & -28 & -60 & 68 & 263 & 0.000 \\
\hline Inferior parietal gyrus & Left & -51 & -40 & 39 & 135 & 0.029 \\
\hline \multicolumn{7}{|l|}{ Negatively correlated } \\
\hline Posterior cerebellum & Left & -45 & -45 & -40 & 352 & 0.014 \\
\hline
\end{tabular}

*FWE TFCE corrected; ${ }^{\#}$ peak coordinates in MNI space; ${ }^{\circledR}$ number of voxels in a cluster

dependent on both the experience and the practice of Silent Mantra meditation (Engstrom et al., 2010). In a functional MRI study of experienced Adept Meditators, greater activation was observed in the medial PFC along with anterior cingulate cortex that is involved in emotional regulation in presence of distracting events (Hölzel et al., 2007). The medial PFC, along with the superior temporal sulcus, is associated with the theory of mind (Den et al., 2005). Generally, the neural circuit of various prefrontal regions and subcortical limbic structures implies emotional self-regulation. Thinking positively and experiencing happiness support the development of the brain by generating and reinforcing new synapses, mainly in PFC which serves as the integration center for mind and brain functions (Susan, 2011). Findings in the current study appear in agreement with prior evidence indicating that RM practice may help in enhancing voluntary regulation of attention, behavior, and emotional selfregulation.

Further, in RM practitioners, a significantly higher GMV was observed in the left inferior OFC when compared with NM. This region involves in emotional regulation and is associated with reward and punishment. OFC, along with the hippocampus and ventral tegmental areas, involves in the reward and motivational process. Learning and adjusting one's behavior in response to a task mainly depends on the function of OFC (Quirk \& Beer, 2006; Wikenheiser \& Schoenbaum, 2016). Increased GMV in OFC was observed in a meditation study suggested that meditators can disengage automatically
Table 3 Correlation of brain regions with positive thinking score in RM practitioners

\begin{tabular}{|c|c|c|c|c|c|c|}
\hline \multirow[t]{2}{*}{ Regions } & \multirow[t]{2}{*}{ Side } & \multicolumn{3}{|c|}{ Coordinates ${ }^{\#}$} & \multirow[t]{2}{*}{ Voxels ${ }^{@}$} & \multirow[t]{2}{*}{$p$-value* } \\
\hline & & $\mathrm{x}$ & $\mathrm{y}$ & $z$ & & \\
\hline
\end{tabular}

Positively correlated

$\begin{array}{lllllll}\text { Superior temporal gyrus } & \text { Right } & 46 & -45 & 22 & 213 & 0.007\end{array}$

Negatively correlated-No negative correlation

*FWE TFCE corrected; * peak coordinates in MNI space; ${ }^{\circledR}$ number of voxels in a cluster

generated thoughts and habits by enhancing emotional selfregulation (Luders et al., 2009). Thus, practicing RM may help motivate the learners to overcome the automatic thought process and maintain emotional self-regulation.

Moreover, a significant increase in the bilateral precuneus was also observed in RM practitioners. Functionally precuneus plays a vital role in self-awareness and attention (Kurth et al., 2014). In a functional study on a group of moderately experienced Silent mantra meditators, increased activation on the right precuneus along with other regions was found during meditation (Engstrom et al., 2010). A functional MRI study by Hernández et al. (2018) observed an increased activity in the bilateral precuneus regions [after removal of covariates] while maintaining mental silence. Yang et al. (2016) reported increased activity of the right precuneus during mindfulness meditation. A questionnaire-based study revealed a positive association between the subjective happiness score and GMV in the right precuneus, which indicates that this region plays a role in mediating subjective happiness by integrating the emotional and cognitive components of happiness (Sato et al., 2015). The striking finding in this study of a significant increase in GMV of the bilateral precuneus in RM practitioners suggests that RM practice may help to enhance self-awareness, attention, and happiness.

Additionally, a significant increase in the left IPG in RM practitioners was observed when compared with NM. A significant positive association of the left SPG and IPG with hours of meditation experience was also observed in the RM group. These regions play an essential role in the perception of
Fig. 4 a Correlation of PT score with normalized hours of meditation experience. $\mathbf{b}$ Box plot showing comparison of PT score with meditation experience among RM practitioners. Longterm RM practitioners had significant PT score $(p=0.029)$ than short-term RM practitioners. PT, positive thoughts. RM, Rajyoga meditation

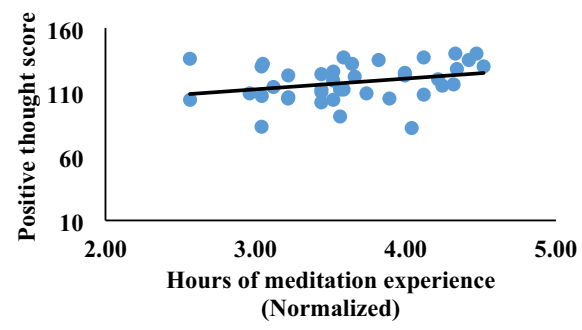

a

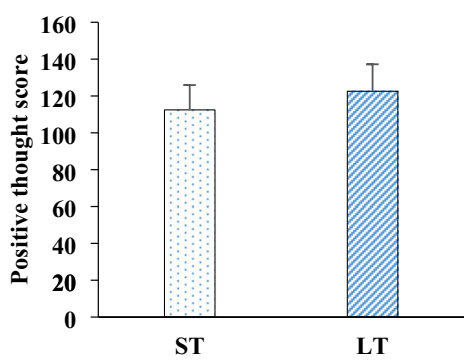

b 

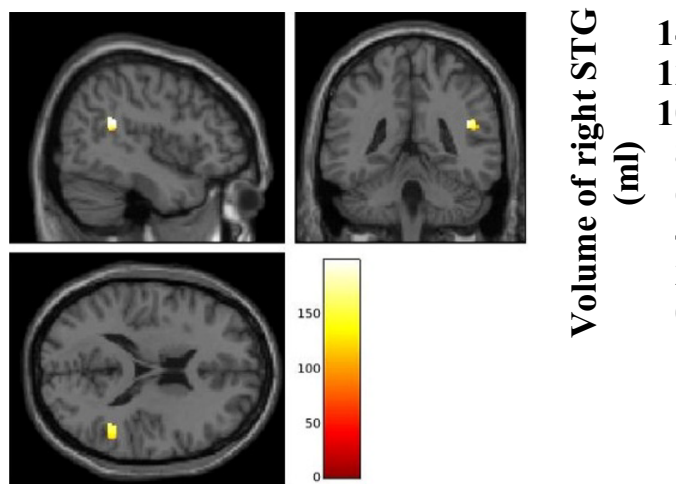

a

Fig. 5 a Representative sMRI image after applying SVC showing significant (FWE TFCE corrected $p<0.05, d f=35$ ) positive correlation of PT scores with the right superior temporal gyrus in RM practitioners. b Scatter plot did not show any significant correlation with extracted regional GMV of right superior temporal gyrus. c Among meditators,

emotion and interpretation of sensory information. Also, these regions help to maintain body image and spatiality with respect to the environment (Bermudez et al., 2017; Singh-Curry \& Husain, 2009). Studies show that the IPG, along with the SPG and STG, involves in voluntary attentional control that is selectively activated by cues (Ding et al., 2015; Hopfinger et al., 2000). Increased GMV in these regions suggests that these regions help to regulate voluntary attention control while maintaining environmental awareness in RM practitioners.

GMV of left MTG showed a significant increase in RM practitioners when compared to the same in NM, indicating that RM practice helps in gaining attentional control. Similar findings, with higher GMV in the left middle and inferior temporal gyrus, were found by Leung et al. (2013) in loving-kindness meditation experts. A study on Brain Wave Vibration practitioners with average of 41 months of meditation experience showed that they have significantly increased cortical thickness in the bilateral middle and inferior temporal gyrus (Kang et al., 2013) and a VBM study on Sahaja Yoga meditation reported a larger GM volume in bilateral inferior temporal gyrus (Hernández et al., 2016). Panda et al. (2016) have reported a higher activity in left MTG along with right MFG in RM practitioners during meditation. These regions typically involve in greater attentional control.

A significant increase in GMV in the bilateral cuneus (a part of the occipital region) was also observed in RM practitioners. Other mediation studies have also identified GM changes in the respective cuneal areas that are responsible for the primary visual perception (Luders et al., 2012; Pickut et al., 2013). Luders et al. (2012) have reported an increased gyrification on the left parietooccipital and right cuneus in meditators. Study on Brain Wave Vibration practitioners also showed a significantly increased cortical thickness and fractional anisotropic values in the cuneus in comparison with controls (Kang et al., 2013). The

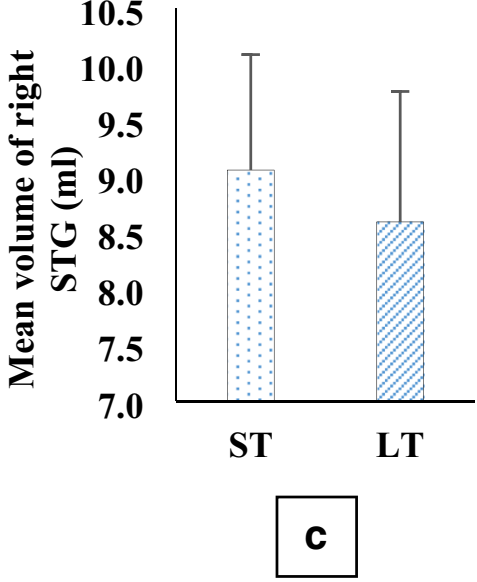

short-term RM practitioners had a higher GMV in the right superior temporal gyrus than long-term RM practitioners. Color bar indicates TFCE values. RM, Rajyoga meditation; PT, positive thoughts; TFCE, threshold-free cluster enhancement; SVC, small volume correction

cuneus involves shifting and maintaining visual attention (Corbetta et al., 1998; Hopfinger et al., 2000; Luders et al., 2012). Since RM is an open-eye meditation practice in which meditators focus their visual attention on the point of light, the observation of a significantly higher GMV in the bilateral cuneus is similar to previous studies as explained.

Additionally, a significantly higher GMV was observed in the left posterior cerebellum when compared with that of the control. An in-depth analysis of the cerebellum by recent research studies indicate its role in cognition and behavior, in addition to traditionally known functions of the cerebellum in the coordination of voluntary movements, gait, posture, speech, and motor functions. Particularly the posterior lobe of the cerebellum subserves the functions of cognition and emotion. A lesion in the posterior lobe causes cerebellar cognitive-affective syndrome (Rapoport et al., 2000; Schmahmann, 2019). The study on mindfulness-based stress reduction has identified a significant increase in GM concentration in the cerebellum along with the PCC and temporoparietal junction which are involved in learning, memory processes, emotion regulation, self-referential processing, and perspective-taking (understanding the concept from an alternate point of view) (Hölzel et al., 2011). Thus, the findings on RM practitioners in this study indicate that the posterior cerebellum is also associated with cognitive learning, thinking positively during RM practice. But, on comparing the GMV changes in cerebellum of RM practitioners based on their duration of Rajyoga meditation experience, a significant negative correlation of the left posterior cerebellum was observed. This negative correlation was particularly higher in short-term RM practitioners when compared to long-term RM practitioners. This may be due to an increase in cerebellar neural plasticity during short-term periods of RM training. But in long-term RM training, there is a decline in the 
neural plasticity of the left cerebellum. It is possibly similar to the changes observed in studies reported on juggler learners where a reduction in the regional GMV after an initial increase in the same region was observed (Boyke et al., 2008; Driemeyer et al., 2008). Thus, RM practice may also regulate the cognitive process via left posterior cerebellum.

A significant positive correlation between PT score and hours of meditation experience was observed in this study, with a higher mean score in long-term than short-term RM practitioners. It has been observed that mindfulness training influences the positive affect of individuals (Jung et al., 2010; Patel et al., 2018). Additionally, a significant positive association between PT scores and GMV of the right STG in RM practitioners was also observed. Similarly, Lazer et al. (2005) have observed an increased cortical thickness in the left STG in meditators. The studies on patients with schizophrenia, characterized by auditory hallucination and thought-related disorders, have identified a significant decrease in the bilateral posterior STG and a positive correlation between thought disorder and decreased GMV in the right anterior STG (Holinger et al., 1999). This indicates that the decreased GMV changes in right STG correlate to thought disorders, whereas an increase in GMV in the same region in RM practitioners is observed to be correlated to higher PT scores. A similar finding in the temporal region indicates that a long-term practice of RM enhances positive thought process and may help to overcome thought related disorders such as schizophrenia and schizoaffective disorders.

Thus, this study provides the initial evidence of the influence of RM practice on GMV changes in specific brain regions that are associated with PT processes. The overall increase in the global GMV in RM provides evidence of meditation-induced neural plasticity in regions that process regulation of self-awareness, behavior, automatic thought process, and visual attention. Thus, the practice of RM enhances GMV changes and PT process, a prerequisite for enhancing happiness and well-being.

\section{Limitations and Future Research}

Among the regional GMV extracted using AAL atlas, shown in Table S1 (Supplementary Materials), statistically significant ( $p$ $<0.05$ ) increase in GMV was observed in the right superior and middle OFC, bilateral recti, right Heschl gyrus, and bilateral inferior occipital gyri in RM practitioners when compared with NM. However, there were no significant differences in these regions either with the voxel-wise comparison with SVC or with whole-brain analysis between RM practitioners and NM. Though a significant difference was not observed in the right SFG in the extracted regional GMV, as shown in Table S1 (Supplementary Materials), a significant difference was found in VBM analysis between RM practitioners and NM. A similar trend was observed in correlation and comparative analysis from the extracted regional GMV among meditators, as shown in Figs. 3b, $c$ and 5b, c. This discrepancy may be due to the size of the cluster or height of the voxels in these regions which is possibly not sufficient to show a significant difference. This discrepancy may be avoided by increasing the sample size of the study. Additionally, a significant increase $(p<0.05)$ in extracted GMV in the left anterior cingulate gyrus was observed in NM, but not with the voxel-wise analysis of both the groups. Though the education levels of the participants were added as a covariate, the hippocampus and amygdala regions did not show any significant differences in both the groups. The levels of education of the participants have a direct or indirect influence on these regions (Kang et al., 2018; Piras et al., 2011; Tang et al., 2017). Thus, the levels of education have a strong confounding effect in brain image analysis. Although both the groups are matched for age, gender, and handedness, the education levels were not matched in the present study. More crosssectional studies with greater sample size and matching for education levels of participants along with other covariables may help to provide stronger evidence of the neural plasticity observed in specific brain regions, particularly associated with PT processes in RM practitioners. Additionally, interventional or follow-up studies with a large sample size may provide stronger confirmative evidence and could also overcome the confounding effect of education level on these findings.

Supplementary Information The online version contains supplementary material available at https://doi.org/10.1007/s12671-021-01630-8.

Acknowledgements We would like to express our gratitude to Rajyoga teachers, BK Sowrabha and BK Sujatha of the Rajyoga Meditation Centre in Manipal for allowing the participants to take part in our study. We appreciate the help of the staffs at Kasturba Hospital, KMC, Manipal, particularly the radiographers from the Department of Radiodiagnosis and Imaging at Kasturba Hospital, KMC, Manipal, for their support. We appreciate the technical assistance provided by Medical Imaging Research Suite supported by Philips, KMC, Manipal.

Author Contribution RMGB, RK, and KSR: contributed in conceptualization and designing the study. RMGB: contributed in collecting and analyzing the data. RK and PK: contributed for MRI sequence setting and data verification. BS: collaborated for data analysis and interpretation. RMGB and KSR: contributed in writing this manuscript. All authors contributed for review and editing of this manuscript.

Funding Open access funding provided by Manipal Academy of Higher Education, Manipal. We gratefully acknowledge the support, invaluable resources, and infrastructure provided by MAHE, Manipal, for this research. We are also grateful to the Rajyoga Education \& Research Foundation (RERF), Mount Abu, Rajasthan, for providing partial financial support and permission to select RM practitioners from Rajyoga Meditation Centre.

\section{Declarations}

Ethics Approval Ethics approval (IEC 566/2013) was received for this study from the institutional ethical committee of Kasturba Hospital, 
MAHE, Manipal. The study's methods were carried out in compliance with the Declaration of Helsinki-World Health Organization's standard ethical guidelines.

Conflict of Interest The authors declare no competing interests.

Open Access This article is licensed under a Creative Commons Attribution 4.0 International License, which permits use, sharing, adaptation, distribution and reproduction in any medium or format, as long as you give appropriate credit to the original author(s) and the source, provide a link to the Creative Commons licence, and indicate if changes were made. The images or other third party material in this article are included in the article's Creative Commons licence, unless indicated otherwise in a credit line to the material. If material is not included in the article's Creative Commons licence and your intended use is not permitted by statutory regulation or exceeds the permitted use, you will need to obtain permission directly from the copyright holder. To view a copy of this licence, visit http://creativecommons.org/licenses/by/4.0/.

\section{References}

Agroskin, D., Klackl, J., \& Jonas, E. (2014). The self-liking brain: A VBM study on the structural substrate of self-esteem. PLoS One, 9(1), e86430. https://doi.org/10.1371/journal.pone.0086430.

Archer, J. A., Lee, A., Qiu, A., \& Chen, S.-H. A. (2018). Working memory, age and education: A lifespan fMRI study. PLoS One, 13(3), e0194878. https://doi.org/10.1371/journal.pone.0194878.

Ashburner, J., \& Friston, K. J. (2000). Voxel-based morphometry - The methods. NeuroImage, 11(6 I), 805-821. https://doi.org/10.1006/ nimg.2000.0582.

Babu, M. G. R., Kadavigere, R., Koteshwara, P., Sathian, B., \& Rai, K. S. (2020). Rajyoga meditation induces grey matter volume changes in regions that process reward and happiness. Scientific Reports, 10(1), 1-11. https://doi.org/10.1038/s41598-020-73221-x.

Bærentsen, K. B., Stødkilde-Jørgensen, H., Sommerlund, B., Hartmann, T., Damsgaard-Madsen, J., Fosnæs, M., \& Green, A. C. (2010). An investigation of brain processes supporting meditation. Cognitive Processing, 11(1), 57-84. https://doi.org/10.1007/s10339-0090342-3.

Bermudez, J., Krizaj, D., Lipschitz, D. L., Bueler, C. E., Rogowska, J., Yurgelun-Todd, D., \& Nakamura, Y. (2017). Externally-induced meditative states: An exploratory fMRI study of architects' responses to contemplative architecture. Frontiers of Architectural Research, 6(2), 123-136. https://doi.org/10.1016/j.foar.2017.02. 002 .

Boller, B., Mellah, S., Ducharme-Laliberté, G., \& Belleville, S. (2017). Relationships between years of education, regional grey matter volumes, and working memory-related brain activity in healthy older adults. Brain Imaging and Behavior, 11(2), 304-317. https://doi. org/10.1007/s11682-016-9621-7.

Boyke, J., Driemeyer, J., Gaser, C., Büchel, C., \& May, A. (2008). Training-induced brain structure changes in the elderly. Journal of Neuroscience, 28(28), 7031-7035. https://doi.org/10.1523/ JNEUROSCI.0742-08.2008.

Brahmakumaris. (2020). What is Raja Yoga meditation? Retrieved March 01, 2021, from https://www.brahmakumaris.com/rajayogameditation/\#

Cabeza, R., \& Nyberg, L. (2000). Imaging cognition II: An empirical review of 275 PET and fMRI studies. Journal of Cognitive Neuroscience, 12(1), 1-47. https://doi.org/10.1162/ 08989290051137585.

Corbetta, M., Akbudak, E., Conturo, T. E., Snyder, A. Z., Ollinger, J. M., Drury, H. A., Linenweber, M. R., Petersen, S. E., Raichle, M. E.,
Van Essen, D. C., \& Shulman, G. L. (1998). A common network of functional areas for attention and eye movements. Neuron, 21(4), 761-773. https://doi.org/10.1016/S0896-6273(00)80593-0.

Davidson, R. J., Jackson, D. C., \& Kalin, N. H. (2000). Emotion, plasticity, context, and regulation: Perspectives from affective neuroscience. Psychological Bulletin, 126(6), 890-909. https://doi.org/10. 1037/0033-2909.126.6.890.

Diener, E., et al. (2009). New measures of well-being. In E. Diener (Ed.), Assessing well-being: Social indicators research series (Vol. 39). Dordrecht: Springer. https://doi.org/10.1007/978-90-481-2354-4 12.

Ding, X., Tang, Y. Y., Cao, C., Deng, Y., Wang, Y., Xin, X., \& Posner, M. I. (2015). Short-term meditation modulates brain activity of insight evoked with solution cue. Social Cognitive and Affective Neuroscience, 10(1), 43-49. https://doi.org/10.1093/scan/nsu032.

Dodich, A., Zollo, M., Crespi, C., Cappa, S. F., Laureiro Martinez, D., Falini, A., \& Canessa, N. (2019). Short-term Sahaja Yoga meditation training modulates brain structure and spontaneous activity in the executive control network. Brain and Behavior: A Cognitive Neuroscience Perspective, 9(1), 1-11. https://doi.org/10.1002/ brb3.1159.

Dreisbach, G. (2006). How positive affect modulates cognitive control: The costs and benefits of reduced maintenance capability. Brain and Cognition, 60(1), 11-19. https://doi.org/10.1016/j.bandc.2005.08. 003 .

Driemeyer, J., Boyke, J., Gaser, C., Büchel, C., \& May, A. (2008). Changes in gray matter induced by learning-Revisited. PLoS One, 3(7), e2669. https://doi.org/10.1371/journal.pone.0002669.

Engen, H. G., Bernhardt, B. C., Skottnik, L., Ricard, M., \& Singer, T. (2018). Structural changes in socio-affective networks: Multi-modal MRI findings in long-term meditation practitioners. Neuropsychologia, 116, 26-33. https://doi.org/10.1016/j. neuropsychologia.2017.08.024.

Engstrom, M., Pihlsgard, J., Lundberg, P., \& Soderfeldt, B. (2010). Functional magnetic resonance imaging of hippocampal activation during silent mantra meditation. Journal of Alternative and Complementary Medicine, 16(12), 1253-1258. https://doi.org/10. 1089/acm.2009.0706.

Fox, K. C. R., Zakarauskas, P., Dixon, M., Ellamil, M., Thompson, E., \& Christoff, K. (2012). Meditation experience predicts introspective accuracy. PLoS One, 7(9). https://doi.org/10.1371/journal.pone. 0045370.

Fox, K. C. R., Dixon, M. L., Nijeboer, S., Girn, M., Floman, J. L., Lifshitz, M., Ellamil, M., Sedlmeier, P., \& Christoff, K. (2016). Functional neuroanatomy of meditation: A review and metaanalysis of 78 functional neuroimaging investigations. Neuroscience and Biobehavioral Reviews, 65, 208-228. https:// doi.org/10.1016/j.neubiorev.2016.03.021.

Frith, C. D., \& Frith, U. (1999). Interacting minds - A biological basis. Science, 286(5445), 1692-1695. https://doi.org/10.1126/science. 286.5445.1692.

Den ., H. E. M., Frith, U., Frith, C., \& Blakemore, S. J. (2005). Thinking about intentions. NeuroImage, 28(4), 787-796. https://doi.org/10. 1016/j.neuroimage.2005.05.001

Froeliger, B., Garland, E. L., \& McClernon, F. J. (2012). Yoga meditation practitioners exhibit greater gray matter volume and fewer reported cognitive failures: Results of a preliminary voxel-based morphometric analysis. Evidence-Based Complementary and Alternative Medicine, 2012. https://doi.org/10.1155/2012/821307

Giedd, J. N., Raznahan, A., Alexander-Bloch, A., Schmitt, E., Gogtay, N., \& Rapoport, J. L. (2014). Child psychiatry branch of the National Institute of Mental Health longitudinal structural magnetic resonance imaging study of human brain development. Neuropsychopharmacology, 40(1), 43-49. https://doi.org/10.1038/ npp.2014.236. 
Grant, J. A., Courtemanche, J., Duerden, E. G., Duncan, G. H., \& Rainville, P. (2010). Cortical thickness and pain sensitivity in Zen meditators. Emotion, 10(1), 43-53. https://doi.org/10.1037/ a0018334.

Grant, J. A., Duerden, E. G., Courtemanche, J., Cherkasova, M., Duncan, G. H., \& Rainville, P. (2013). Cortical thickness, mental absorption and meditative practice: Possible implications for disorders of attention. Biological Psychology, 92(2), 275-281. https://doi.org/10. 1016/j.biopsycho.2012.09.007.

Gupta, S. K., Sawhney, R. C., Rai, L., Chavan, V. D., Dani, S., Arora, R. C., Selvamurthy, W., Chopra, H. K., \& Nanda, N. C. (2011). Regression of coronary atherosclerosis through healthy lifestyle in coronary artery disease patients - Mount Abu open heart trial. Indian Heart Journal, 63(5), 461-469. https://doi.org/10.4172/2155-9880. S1.021.

Hauswald, A., Übelacker, T., Leske, S., \& Weisz, N. (2015). What it means to be Zen: Marked modulations of local and interareal synchronization during open monitoring meditation. NeuroImage, 108, 265-273. https://doi.org/10.1016/j.neuroimage.2014.12.065.

Hernández, S. E., Suero, J., Barros, A., González-Mora, J. L., \& Rubia, K. (2016). Increased grey matter associated with long-term Sahaja yoga meditation: A voxel-based morphometry study. PLoS One, 11(3), e0150757. https://doi.org/10.1371/journal.pone.0150757.

Hernández, S. E., Barros-Loscertales, A., Xiao, Y., González-Mora, J. L., \& Rubia, K. (2018). Gray matter and functional connectivity in anterior cingulate cortex are associated with the state of mental silence during Sahaja Yoga meditation. Neuroscience, 371, 395-406. https://doi.org/10.1016/j.neuroscience.2017.12.017.

Holinger, D. P., Shenton, M. E., Wible, C. G., Donnino, R., Kikinis, R., Jolesz, F. A., \& McCarley, R. W. (1999). Superior temporal gyrus volume abnormalities and thought disorder in left-handed schizophrenic men. American Journal of Psychiatry, 156(11), 1730-1735. https://doi.org/10.1176/ajp.156.11.1730.

Hölzel, B. K., Ott, U., Hempel, H., Hackl, A., Wolf, K., Stark, R., \& Vaitl, D. (2007). Differential engagement of anterior cingulate and adjacent medial frontal cortex in adept meditators and non-meditators. Neuroscience Letters, 421(1), 16-21. https://doi.org/10.1016/j. neulet.2007.04.074.

Hölzel, B. K., Ott, U., Gard, T., Hempel, H., Weygandt, M., Morgen, K., \& Vaitl, D. (2008). Investigation of mindfulness meditation practitioners with voxel-based morphometry. Social Cognitive and Affective Neuroscience, 3(1), 55-61. https://doi.org/10.1093/scan/ nsm038.

Hölzel, B. K., Carmody, J., Vangel, M., Congleton, C., Yerramsetti, S. M., Gard, T., \& Lazar, S. W. (2011). Mindfulness practice leads to increases in regional brain gray matter density. Psychiatry Research: Neuroimaging, 191(1), 36-43. https://doi.org/10.1016/j. pscychresns.2010.08.006.

Hopfinger, J. B., Buonocore, M. H., \& Mangun, G. R. (2000). The neural mechanisms of top-down attentional control. Nature Neuroscience, 3(3), 284-291. https://doi.org/10.1038/72999.

Jung, Y. H., Kang, D. H., Jang, J. H., Park, H. Y., Byun, M. S., Kwon, S. J., Jang, G. E., Lee, U. S., An, S. C., \& Kwon, J. S. (2010). The effects of mind-body training on stress reduction, positive affect, and plasma catecholamines. Neuroscience Letters, 479(2), 138-142. https://doi.org/10.1016/j.neulet.2010.05.048.

Kang, D. H., Jo, H. J., Jung, W. H., Kim, S. H., Jung, Y. H., Choi, C. H., Lee, U. S., An, S. C., Jang, J. H., \& Kwon, J. S. (2013). The effect of meditation on brain structure: Cortical thickness mapping and diffusion tensor imaging. Social Cognitive and Affective Neuroscience, 8(1), 27-33. https://doi.org/10.1093/scan/nss056.

Kang, D. W., Lim, H. K., Joo, S. H., Lee, N. R., \& Lee, C. U. (2018). The association between hippocampal subfield volumes and education in cognitively normal older adults and amnestic mild cognitive impairment patients. Neuropsychiatric Disease and Treatment, 14, 143152. https://doi.org/10.2147/NDT.S151659.
Korponay, C., Dentico, D., Kral, T. R. A., Ly, M., Kruis, A., Davis, K., Goldman, R., Lutz, A., \& Davidson, R. J. (2019). The effect of mindfulness meditation on impulsivity and its neurobiological correlates in healthy adults. Scientific Reports, 9(1), 1-17. https://doi. org/10.1038/s41598-019-47662-y.

Kurth, F., Luders, E., Wu, B., \& Black, D. S. (2014). Brain gray matter changes associated with mindfulness meditation in older adults: An exploratory pilot study using voxel-based morphometry. Neuro, 1(1), 23-26. https://doi.org/10.17140/noj-1-106.

Kurth, F., MacKenzie-Graham, A., Toga, A. W., \& Luders, E. (2015). Shifting brain asymmetry: The link between meditation and structural lateralization. Social Cognitive and Affective Neuroscience, 10(1), 55-61. https://doi.org/10.1093/scan/nsu029.

Lazar, S. W., Kerr, C. E., Wasserman, R. H., Gray, J. R., Greve, D. N., Treadway, M. T., McGarvey, M., Quinn, B. T., Dusek, J. A., Benson, H., Rauch, S. L., Moore, C. I., \& Fischl, B. (2005). Meditation experience is associated with increased cortical thickness. NeuroReport, 16(17), 1893-1897. https://doi.org/10.1097/01. wnr.0000186598.66243.19.

Lenroot, R. K., Gogtay, N., Greenstein, D. K., Wells, E. M., Wallace, G. L., Clasen, L. S., Blumenthal, J. D., Lerch, J., Zijdenbos, A. P., Evans, A. C., Thompson, P. M., \& Giedd, J. N. (2007). Sexual dimorphism of brain developmental trajectories during childhood and adolescence. NeuroImage, 36(4), 1065-1073. https://doi.org/ 10.1016/j.neuroimage.2007.03.053.

Leung, M.-K., Chan, C. C. H., Yin, J., Lee, C.-F., So, K.-F., \& Lee, T. M. C. (2013). Increased gray matter volume in the right angular and posterior parahippocampal gyri in loving-kindness meditators. Social Cognitive and Affective Neuroscience, 8(1), 34-39. https:// doi.org/10.1093/scan/nss076.

Li, H., Nickerson, L. D., Nichols, T. E., \& Gao, J.-H. (2017). Comparison of a non-stationary voxelation-corrected cluster-size test with TFCE for group-Level MRI inference. Human Brain Mapping, 38(3), 1269-1280. https://doi.org/10.1002/hbm.23453.

Luders, E., Toga, A. W., Lepore, N., \& Gaser, C. (2009). The underlying anatomical correlates of long-term meditation: Larger hippocampal and frontal volumes of gray matter. NeuroImage, 45(3), 672-678. https://doi.org/10.1016/j.neuroimage.2008.12.061.

Luders, E., Clark, K., Narr, K. L., \& Toga, A. W. (2011). Enhanced brain connectivity in long-term meditation practitioners. NeuroImage, 57(4), 1308-1316. https://doi.org/10.1016/j.neuroimage.2011.05. 075 .

Luders, E., Kurth, F., Mayer, E. A., Toga, A. W., Narr, K. L., \& Gaser, C. (2012). The unique brain anatomy of meditation practitioners: Alterations in cortical gyrification. Frontiers in Human Neuroscience, 6, 34. https://doi.org/10.3389/fnhum.2012.00034.

Lutz, A., Slagter, H. A., Dunne, J. D., \& Davidson, R. J. (2008). Attention regulation and monitoring in meditation. Trends in Cognitive Sciences, 12(4), 163-169. https://doi.org/10.1016/j.tics.2008.01.005

May, A., Hajak, G., Gänßbauer, S., Steffens, T., Langguth, B., Kleinjung, T., \& Eichhammer, P. (2007). Structural brain alterations following 5 days of intervention: Dynamic aspects of neuroplasticity. Cerebral Cortex, 17(1), 205-210. https://doi.org/10.1093/cercor/bhj138.

McAlonan, G. M., Cheung, V., Cheung, C., Suckling, J., Lam, G. Y., Tai, K. S., Yip, L., Murphy, D. G. M., \& Chua, S. E. (2005). Mapping the brain in autism. A voxel-based MRI study of volumetric differences and intercorrelations in autism. Brain, 128(2), 268-276. https://doi.org/10.1093/brain/awh332.

Mills, K. L., \& Tamnes, C. K. (2014). Methods and considerations for longitudinal structural brain imaging analysis across development. Developmental Cognitive Neuroscience, 9, 172-190. https://doi.org/ 10.1016/j.den.2014.04.004.

Nair, A. K., Sasidharan, A., John, J. P., Mehrotra, S., \& Kutty, B. M. (2017). Just a minute meditation: Rapid voluntary conscious state shifts in long term meditators. Consciousness and Cognition, 53, 176-184. https://doi.org/10.1016/j.concog.2017.06.002. 
Newberg, A. B., \& Iversen, J. (2003). The neural basis of the complex mental task of meditation: Neurotransmitter and neurochemical considerations. Medical Hypotheses, 61(2), 282-291. https://doi.org/10. 1016/S0306-9877(03)00175-0

Panda, R., Bharath, R. D., Upadhyay, N., Mangalore, S., Chennu, S., \& Rao, S. L. (2016). Temporal dynamics of the default mode network characterize meditation-induced alterations in consciousness. Frontiers in Human Neuroscience, 10(July), 372. https://doi.org/ 10.3389/fnhum.2016.00372.

Patel, N. K., Nivethitha, L., \& Mooventhan, A. (2018). Effect of a yoga based meditation technique on emotional regulation, selfcompassion and mindfulness in college students. Explore (New York, N.Y.), 14(6), 443-447. https://doi.org/10.1016/j.explore. 2018.06.008.

Pickut, B. A., Van Hecke, W., Kerckhofs, E., Mariën, P., Vanneste, S., Cras, P., \& Parizel, P. M. (2013). Mindfulness based intervention in Parkinson's disease leads to structural brain changes on MRI: a randomized controlled longitudinal trial. Clinical Neurology and Neurosurgery, 115(12), 2419-2425. https://doi.org/10.1016/j. clineuro.2013.10.002.

Piras, F., Cherubini, A., Caltagirone, C., \& Spalletta, G. (2011). Education mediates microstructural changes in bilateral hippocampus. Human Brain Mapping, 32(2), 282-289. https://doi.org/10. 1002/hbm.21018.

Pliatsikas, C. (2020). Understanding structural plasticity in the bilingual brain: The dynamic restructuring model. Bilingualism, 23(2), 459471. https://doi.org/10.1017/S1366728919000130

Quirk, G. J., \& Beer, J. S. (2006). Prefrontal involvement in the regulation of emotion: Convergence of rat and human studies. Current Opinion in Neurobiology, 16(6), 723-727. https://doi.org/10.1016/j.conb. 2006.07.004.

Ramesh, M. G., Sathian, B., Sinu, E., \& Rai, K. S. (2013). Efficacy of Rajayoga meditation on positive thinking: An index for selfsatisfaction and happiness in life. Journal of Clinical and Diagnostic Research, 7(10), 2265-2267. https://doi.org/10.7860/ JCDR/2013/5889.3488.

Ramsay, T., Manderson, L., \& Smith, W. (2010). Changing a mountain into a mustard seed: Spiritual practices and responses to disaster among New York Brahma Kumaris. Journal of Contemporary Religion, 25(1), 89-105. https://doi.org/10.1080/ 13537900903416838.

Rapoport, M., Van Reekum, R., \& Mayberg, H. (2000). The role of the cerebellum in cognition and behavior: A selective review. Journal of Neuropsychiatry and Clinical Neurosciences, 12(2), 193-198. https://doi.org/10.1176/jnp.12.2.193.

Raschle, N. M., Menks, W. M., Fehlbaum, L. V., Steppan, M., Smaragdi, A., Gonzalez-Madruga, K., Rogers, J., Clanton, R., Kohls, G., Martinelli, A., Bernhard, A., Konrad, K., Herpertz-Dahlmann, B., Freitag, C. M., Fairchild, G., De Brito, S. A., \& Stadler, C. (2018). Callous-unemotional traits and brain structure: Sex-specific effects in anterior insula of typically-developing youths. NeuroImage: Clinical, 17, 856-864. https://doi.org/10.1016/j.nicl.2017.12.015.

Sato, W., Kochiyama, T., Uono, S., Kubota, Y., Sawada, R., Yoshimura, S., \& Toichi, M. (2015). The structural neural substrate of subjective happiness. Scientific Reports, 5, 16891. https://doi.org/10.1038/ srep16891.

Schlaug, G. (2015). Musicians and music making as a model for the study of brain plasticity. Progress in Brain Research, 217, 37-55. https:// doi.org/10.1016/bs.pbr.2014.11.020.

Schmahmann, J. D. (2019). The cerebellum and cognition. Neuroscience Letters, 688, 62-75. https://doi.org/10.1016/j.neulet.2018.07.005.

Sharma, K., Trivedi, R., Chandra, S., Kaur, P., Kumar, P., Singh, K., Dubey, A. K., \& Khushu, S. (2018). Enhanced white matter integrity in corpus callosum of long-term Brahmakumaris Rajayoga meditators. Brain Connectivity, 8(1), 49-55. https://doi. org/10.1089/brain.2017.0524.

Singh-Curry, V., \& Husain, M. (2009). The functional role of the inferior parietal lobe in the dorsal and ventral stream dichotomy. Neuropsychologia, 47(6), 1434-1448. https://doi.org/10.1016/j. neuropsychologia.2008.11.033.

Smith, S. M., \& Nichols, T. E. (2009). Threshold-free cluster enhancement: Addressing problems of smoothing, threshold dependence and localisation in cluster inference. NeuroImage, 44(1), 83-98. https://doi.org/10.1016/j.neuroimage.2008.03.061.

Streit, W. J., Sammons, N. W., Kuhns, A. J., \& Sparks, D. L. (2004). Dystrophic microglia in the aging human brain. GLIA, 45(2), 208212. https://doi.org/10.1002/glia.10319.

Susan, R. (2011). Happy brain, happy life. Positive psychology. https:// www.psychologytoday.com/us/blog/prime-your-gray-cells/ 201108/happy-brain-happy-life. Accessed 29 Sept 2019.

Tang, Y. Y., Ma, Y., Wang, J., Fan, Y., Feng, S., Lu, Q., Yu, Q., Sui, D., Rothbart, M. K., Fan, M., \& Posner, M. I. (2007). Short-term meditation training improves attention and self-regulation. Proceedings of the National Academy of Sciences of the United States of America, 104(43), 17152-17156. https://doi.org/10.1073/pnas. 0707678104

Tang, J., Liao, Y., Zhou, B., Tan, C., Liu, W., Wang, D., Liu, T., Hao, W., Tan, L., \& Chen, X. (2012). Decrease in temporal gyrus gray matter volume in first-episode, early onset schizophrenia: An MRI study. PLoS One, 7(7), e40247. https://doi.org/10.1371/journal.pone.0040247.

Tang, Y. Y., Hölzel, B. K., \& Posner, M. I. (2015). The neuroscience of mindfulness meditation. Nature Reviews Neuroscience, 16(4), 213 225. https://doi.org/10.1038/nrn3916.

Tang, X., Varma, V. R., Miller, M. I., \& Carlson, M. C. (2017). Education is associated with sub-regions of the hippocampus and the amygdala vulnerable to neuropathologies of Alzheimer's disease. Brain Structure and Function, 222(3), 1469-1479. https://doi.org/10. 1007/s00429-016-1287-9.

Telles, S., Joseph, C., Venkatesh, S., \& Desiraju, T. (1993). Alterations of auditory middle latency evoked potentials during yogic consciously regulated breathing and attentive state of mind. International Journal of Psychophysiology, 14(3), 189-198. https://doi.org/10. 1016/0167-8760(93)90033-1.

Vestergaard-Poulsen, P., Van Beek, M., Skewes, J., Bjarkam, C. R., Stubberup, M., Bertelsen, J., \& Roepstorff, A. (2009). Long-term meditation is associated with increased gray matter density in the brain stem. NeuroReport, 20(2), 170-174. https://doi.org/10.1097/ WNR.0b013e328320012a.

Wang, X. P., Liu, J. M., \& Zhao, Y. B. (2008). Migraine: Sex-influenced trait model? Medical Hypotheses, 71(1), 14-21. https://doi.org/10. 1016/j.mehy.2007.12.015.

Wikenheiser, A. M., \& Schoenbaum, G. (2016). Over the river, through the woods: Cognitive maps in the hippocampus and orbitofrontal cortex. Nature Reviews Neuroscience, 17(8), 513-523. https://doi. org/10.1038/nrn.2016.56.

Yang, C. C., Barrós-Loscertales, A., Pinazo, D., Ventura-Campos, N., Borchardt, V., Bustamante, J. C., Rodríguez-Pujadas, A., FuentesClaramonte, P., Balaguer, R., Ávila, C., \& Walter, M. (2016). State and training effects of mindfulness meditation on brain networks reflect neuronal mechanisms of its antidepressant effect. Neural Plasticity, 2016. https://doi.org/10.1155/2016/9504642.

Publisher's Note Springer Nature remains neutral with regard to jurisdictional claims in published maps and institutional affiliations. 